\title{
Prediction of In Vivo Atenolol Removal by High-Permeability Hemodialysis Based on an In Vitro Model
}

\author{
Kahina Daheb ${ }^{1}$, Jean-Philippe Lecours ${ }^{2}$, Mark L. Lipman ${ }^{3}$, Patrice Hildgen ${ }^{4}$, Julie J. Roy ${ }^{1}$ \\ ${ }^{1}$ Department of Pharmacy, Jewish General Hospital, Montreal, Canada. ${ }^{2}$ Pharmacie V. Cadorette, A. Lecours \& J.-P. \\ Lecours, Joliette, Canada. ${ }^{3}$ Department of Nephrology, Jewish General Hospital, Montreal, Canada. ${ }^{4}$ Faculté de pharmacie, \\ Université de Montréal, Montreal, Canada.
}

Received, June 15, 2013; Revised, July 12, 2013; Accepted, October 31, 2013; Published, November 6, 2013.

\begin{abstract}
Purpose. In order to update our data on drug dialyzability using the high-permeability dialysis membranes, atenolol elimination by an in vitro dialysis model was compared to that observed in six patients during high-permeability hemodialysis (HD), and the predictive value of the model was evaluated. Methods. Atenolol clearance was evaluated in six patients undergoing chronic HD. They were considered as eligible candidates if they were between 18 and 80 years of age, had a body mass index between 19 and $30 \mathrm{~kg} / \mathrm{m}^{2}$, underwent HD and were taking atenolol on a regular basis in oral tablet form for at least 1 month before the study started. Atenolol clearance was also evaluated in three in vitro dialysis sessions with high-permeability polysulfone membrane. Atenolol was dissolved in $6 \mathrm{~L}$ of Krebs-Henseleit buffer with bovine serum albumin. Dialysis parameters were set to mirror as much as possible the patients' parameters (flow rate: $300 \mathrm{~mL} / \mathrm{min}$, dialyzate flow: $500 \mathrm{~mL} / \mathrm{min}$ ). After sample collection, drug concentrations were measured with high performance liquid chromatography. The comparison between in vivo and in vitro atenolol elimination kinetics was performed by drawing the curve fittings of concentrations $v s$. time on SigmaPlot 12, and adding a $95 \%$ prediction interval to each elimination curve fitting. Results. Mean dialysis clearance of atenolol in vitro and in vivo was $198 \pm 4$ and $235 \pm 53 \mathrm{~mL} / \mathrm{min}$, respectively. Atenolol was significantly removed within the study time period in both in vitro and in vivo experiments. By the end of in vitro dialysis, atenolol remaining in the drug reservoir was less than $2 \%$ of initial arterial concentration. Conclusion. Our study has indicated that atenolol is almost entirely cleared during high-permeability hemodialysis. Furthermore, the in vitro prediction interval of the drug elimination curve fitting could forecast its in vivo elimination especially at the end of dialysis.
\end{abstract}

This article is open to POST-PUBLICATION REVIEW. Registered readers (see "For Readers") may comment by clicking on ABSTRACT on the issue's contents page.

\section{INTRODUCTION}

Currently, high-permeability dialysis techniques are widely used. However, there is little data available on the removal of medications using these techniques. The preponderance of existing data pertains to conventional dialysis techniques and may now be obsolete (1). It is critical for optimal patient care to update our understanding of drug elimination using the high-permeability hemodialysis (HD).

According to the United States Renal Data System, cardiovascular diseases (CVD) accounted for approximately $38 \%$ of mortality in HD patients between 2007 and 2009 (2). Among the most prescribed cardiac drugs in patients with end-stage renal disease (ESRD) (angiotensin-converting enzyme inhibitors, angiotensin receptor blockers, statins, aspirin and clopidogrel); only $\beta$-blockers have been associated with improvements in mortality (3). $\beta$-Blocker treatment of CVD in ESRD patients has expanded rapidly in a relatively short time frame (2).

Although the benefits of $\beta$-blockers are clear, attention must be paid to possible elimination through the filtration membrane to optimize their dosing in HD patients (3-6). Dialysis drug clearance $\left(C L_{D}\right)$ is a measure of how effectively a dialyser can remove drugs from the blood (7). The extent to which a drug is impacted by dialysis is determined by many factors, including drug characteristics (e.g., molecular weight, protein-binding, volume of distribution, water solubility), mechanical

Corresponding Author: Julie J. Roy; Department of Pharmacy, Jewish General Hospital, Montreal, Canada; Email: jroy@j,jgh.mcgill.ca 
properties of dialysis systems (e.g., membrane surface area and thickness, porosity, geometry), and dialysis conditions (e.g., blood and dialyzate flow rates) $(1,7)$.

Quantitative extrapolation of elimination data from one study to another may be difficult because of dialysis system variability and conditions (7). Furthermore, clinical investigations of drug removal are costly and often impractical because of ethical concerns. In fact, it may be hazardous to patients' health to alter their dialysis parameters beyond certain values. Hence, it would be of great value to assess the impact of dialysis conditions on drug clearance. An in vitro approach to quantify drug elimination during dialysis could be rapid and costeffective. It would allow us to freely choose and modulate multiple dialysis parameters, such as blood flow and the ultrafiltration rate (UFR), to examine their impact on $\mathrm{CL}_{\mathrm{D}}$. Before proposing an in vitro model of drug removal, validation is needed to determine its predictive ability by extrapolation to patients. Thus, our objective was to compare drug elimination during $\mathrm{HD}$ in vivo to an in vitro system and to evaluate its predictive value. Atenolol, a $\beta$-blocker prescribed frequently to ESRD patients, was chosen as model drug for this study.

\section{METHODS}

\section{In vitro dialysis system}

The chosen method for the evaluation of drug removal in vitro was adapted from the literature, and was repeated three times $(8,9)$. Atenolol was dissolved in $6 \mathrm{~L}$ of Krebs-Henseleit buffer containing $32 \mathrm{~g} / \mathrm{L}$ of bovine serum albumin (BSA) (10). Its initial concentration was $67 \mathrm{mg} / \mathrm{L}$. Atenolol was purchased from Sigma-Aldrich (St. Louis, MO, USA), and BSA was procured from BioShop (Burlington, ON, Canada). The drug reservoir was equipped with a constant magnetic stirrer and maintained at $37^{\circ} \mathrm{C}$. Polyvinyl chloride tubing, identical to that used for patients, connected the reservoir to the dialyser and back. The former tubing served as the "arterial line", and the latter tubing as the "venous line", providing a closed loop system (Figure 1).

Dialysis was undertaken with a Tina ${ }^{\circledR}$ or Aurora ${ }^{\circledR}$ dialyser (Baxter Inc., Mississauga, ON, Canada), and a polysulfone Optiflux ${ }^{\circledR}$ F160 NR membrane (Fresenius Medical Care North America, Lexington, MA, USA). They were set as follows: dialysis duration $=180 \mathrm{~min}$, reservoir solution flow rate $\left(Q_{\mathrm{a}}\right)=300 \mathrm{~mL} / \mathrm{min}$ and dialyzate flow rate $\left(Q_{\mathrm{d}}\right)$ $=500 \mathrm{~mL} / \mathrm{min}$. The UFR was $0.11 \mathrm{~L} / \mathrm{h}$. Three-mL samples were collected from both the arterial and venous lines before and at 5, 10, 20, 30, 60, 90, 120, 150 and 180 min during dialysis. Samples were frozen at $-20^{\circ} \mathrm{C}$ until analyzed.

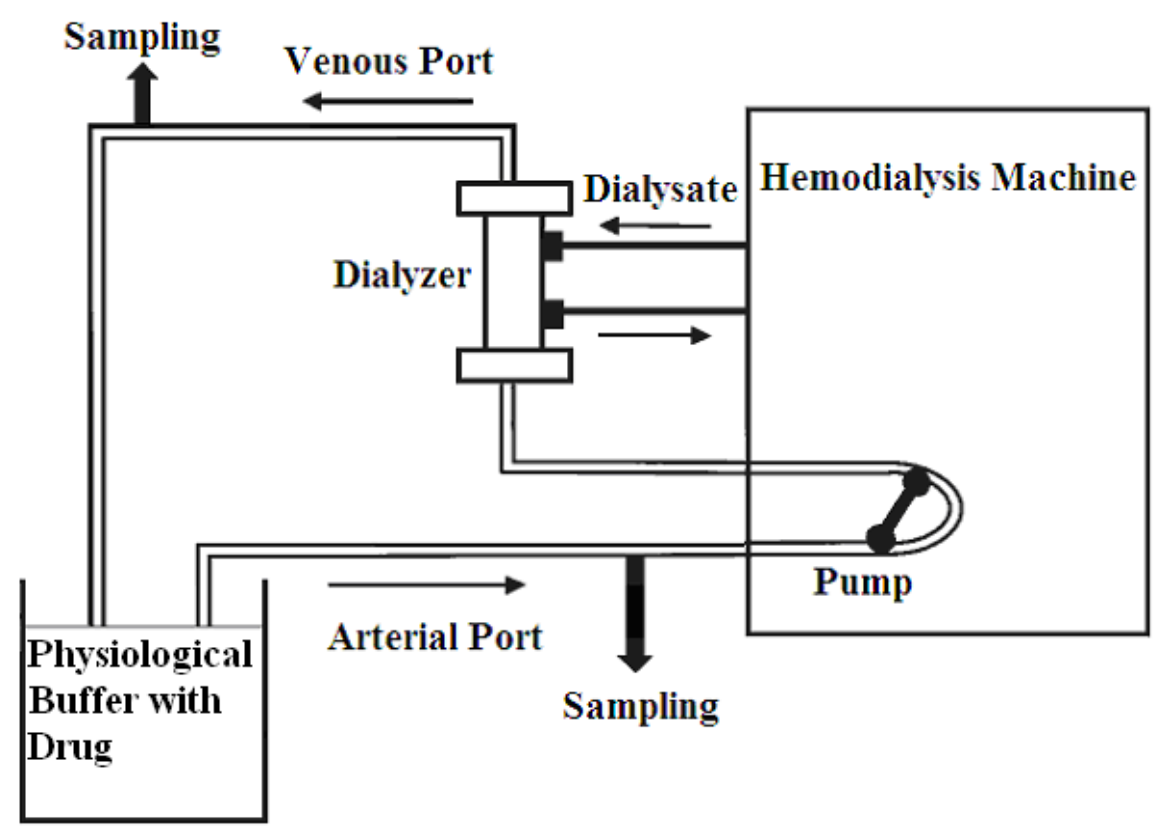

Figure 1. In vitro dialysis set up. 
The liquid-liquid extraction method of Yilmaz et al. was adapted (11). One $\mathrm{mL}$ of each sample was introduced into a glass tube, followed by $10 \mu \mathrm{L}$ of metoprolol tartrate (Sigma-Aldrich) as internal standard at a concentration of $10 \mu \mathrm{g} / \mathrm{mL}$ and 200 $\mu \mathrm{L} \mathrm{NaOH} 1 \mathrm{M}$. Samples were vortex-mixed for 15 $\mathrm{s}$. Seven $\mathrm{mL}$ of an ethyl acetate and diethyl ether 2:1 (v/v) mixture were added to all tubes, which were shaken horizontally for $30 \mathrm{~min}$ before 10 -min centrifugation at $1750 \mathrm{~g}$. Six $\mathrm{mL}$ of the upper organic layer were transferred to another set of clean glass tubes and evaporated to dryness in a SpeedVac at medium temperature at around 40$45^{\circ} \mathrm{C}$. Dry residues were dissolved in $1 \mathrm{~mL}$ of distilled water and vortex-mixed for $30 \mathrm{~s}$. The reconstituted samples were subjected to $0.45 \mu \mathrm{m}$ nylon syringe filtration (Millex, Fisher, Mississauga, ON, Canada) and transferred to highperformance liquid chromatography (HPLC) vials for analysis.

Drug concentrations were quantified by HPLC with ultraviolet (UV) detection in a Shimadzu Prominence UFLC chromatographic system (Shimadzu Corporation, Tokyo, Japan) with a Phenomenex column (HyperClone $5 \mu$ BDS C8 130A $150 \times 4.60 \mathrm{~mm} 5$ microns). The mobile phase consisted of A (methanol with $0.1 \%$ trifluoroacetic acid) and $\mathrm{B}$ (water with $0.1 \%$ trifluoroacetic acid). Gradient conditions were: initial 0-10 min linear change from A-B $(15: 85 \mathrm{v} / \mathrm{v})$ to A-B $(60: 40 \mathrm{v} / \mathrm{v})$, $10-11$ min linear change from $A-B(60: 40 \mathrm{v} / \mathrm{v})$ to A-B (15:85 v/v), and 11-13 min isocratic elution AB $(15: 85 \mathrm{v} / \mathrm{v})$. The mobile phase was pumped at a flow rate of $1 \mathrm{~mL} / \mathrm{min}$. Injection volume was $20 \mu \mathrm{L}$. Detector wave length was set at $223 \mathrm{~nm}$ and oven temperature at $30^{\circ} \mathrm{C}$. The limit of quantitation at minimal UFR was $1 \mu \mathrm{g} / \mathrm{mL}$ for atenolol.

\section{In vitro drug clearance}

Drug concentrations were quantified by plotting the area obtained for each sample against a calibration curve. Correlations between peak areas and drug concentrations were linear for the full range of calibration curve concentrations. The correlation coefficients were superior to $0.98\left(\mathrm{r}^{2}>0.98\right)$. Coefficients of variation for quality control were less than 4\%. Drug clearance during dialysis was calculated as follows:

$$
\mathrm{CL}_{\mathrm{D}}=\left[\left(Q_{\mathrm{a}} \times C_{\mathrm{a}}\right)-\left(Q_{\mathrm{v}} \times C_{\mathrm{v}}\right)\right] / C_{\mathrm{a}}
$$

where $Q_{\mathrm{a}}$ was the arterial blood flow rate, $C_{\mathrm{a}}$ was drug concentration in the arterial line, $Q_{\mathrm{v}}$ was the difference between $Q_{\mathrm{a}}$ and UFR, and $C_{\mathrm{v}}$ was drug concentration in the venous line (7). $C L_{D}$ was calculated at each sampling time. A Trapeze area integration method was employed to compute average $C L_{D}$ in the dialysis sessions.

\section{In vivo dialysis}

This prospective study was approved by the Research Ethics Committee of the Hospital. Atenolol clearance was evaluated in six patients undergoing chronic HD after they gave their written informed consent. They were considered as eligible candidates if they were between 18 and 80 years of age, had a body mass index between 19 and 30 $\mathrm{kg} / \mathrm{m}^{2}$, underwent HD thrice_weekly under fistula access for approximately four hours per session and were taking atenolol on a regular basis in oral tablet form for at least 1 month before the study started. They also needed to consent to take atenolol, once only, 1 to $2 \mathrm{~h}$ prior to the start of their dialysis sessions. The exclusion criteria were: clinicallyrelevant arrhythmias, NYHA II-IV heart failure, unstable angina pectoris, stroke or myocardial infarction within 6 months of study commencement. Single daily atenolol doses ranged from 25 to $100 \mathrm{mg}$. HD conditions (UFR, blood flow rate) varied between patients (Table 1). For patient \#2, UFR was set to mirror plasma sodium concentrations to increase hemodynamic tolerability of dialysis.

Five-mL blood samples were collected just before the start of dialysis and at 30, 60, 90 and 120 min thereafter via both the arterial and venous lines of the dialyser except in patients 4 and 6 receiving lower atenolol doses, for whom sampling times were before the start of and at 15, 30,60 and $90 \mathrm{~min}$ during HD. Blood samples were collected in $10-\mathrm{mL}$ Becton-Dickinson vacutainer tubes (\#367874, Becton-Dickinson Canada Inc., Montreal QC, Canada) containing 143 USP units of heparin. The samples were placed in an ice-water bath for a maximum of $45 \mathrm{~min}$ until they were centrifuged at $2000 \mathrm{~g}$ for $10 \mathrm{~min}$. Plasma was frozen at $-25^{\circ} \mathrm{C}$ until analyzed. 
Table 1. Patient Demographics and Dialysis Parameters

\begin{tabular}{llllllllll}
\hline Pt\# & $\begin{array}{l}\text { Age } \\
(\mathrm{Yrs})\end{array}$ & $\begin{array}{l}\text { Gender } \\
(\mathrm{M} / \mathrm{F})\end{array}$ & $\begin{array}{l}\text { Pre- } \\
\text { dialysis } \\
\text { weight } \\
(\mathrm{kg})\end{array}$ & $\begin{array}{l}\text { Target } \\
\text { weight } \\
\text { removed } \\
(\mathrm{kg})\end{array}$ & $\begin{array}{l}\text { UFR } \\
(\mathrm{L} / \mathrm{h})\end{array}$ & $\begin{array}{l}\text { Blood } \\
\text { flow rate } \\
(\mathrm{mL} / \mathrm{min})\end{array}$ & $\begin{array}{l}\text { Tialyzate } \\
\text { flow rate } \\
(\mathrm{mL} / \mathrm{min})\end{array}$ & $\begin{array}{l}\text { Time } \\
\text { interval } \\
\text { from last } \\
\text { dose to } \\
\text { dialysis }(\mathrm{h})\end{array}$ & $\begin{array}{l}\text { Daily } \\
\text { atenolol } \\
\text { dose } \\
(\mathrm{mg})\end{array}$ \\
\hline 1 & 36 & $\mathrm{~F}$ & 44.5 & 3 & 0.55 & 400 & 500 & 2.5 & 50 \\
2 & 61 & $\mathrm{M}$ & 91.4 & 4 & Profiled & 350 & 700 & 1.72 & 100 \\
3 & 38 & $\mathrm{M}$ & 65.9 & 3 & 0.8 & 500 & 500 & 1.83 & 50 \\
4 & 36 & $\mathrm{~F}$ & 63.5 & 1.5 & 0.68 & 400 & 800 & 1.5 & 25 \\
5 & 79 & $\mathrm{~F}$ & 41.5 & 2.8 & 0.93 & 350 & 500 & 1.25 & 50 \\
6
\end{tabular}

$100 \mu \mathrm{L}$ of metoprolol stock solution and $100 \mu \mathrm{L}$ $\mathrm{NaOH} 1 \mathrm{~N}$ were added successively to $900 \mu \mathrm{L}$ of each standard (atenolol-free plasma spiked with known amounts of atenolol) or $1,000 \mu \mathrm{L}$ plasma test samples. After brief, manual mixing, $6 \mathrm{~mL}$ of chloroform-pentanol 3:1 were incorporated for extraction by manual shaking for $20 \mathrm{~s}$. The tubes were then centrifuged at $3000 \mathrm{~g}$ for $10 \mathrm{~min}$. Subsequently, the aqueous supernatant was discarded and the organic phase was transferred to test tubes after passage through a $0.22-\mu \mathrm{m}$ syringe filter (Millex SLGV 013, Fisher, Mississauga, ON, Canada). The back extraction procedure consisted of adding $250 \mu \mathrm{L}$ of $\mathrm{H}_{2} \mathrm{SO}_{4} 0.5 \mathrm{~N}$ to the organic phase with vortex mixing for $20 \mathrm{~s}$. The tubes were again centrifuged at $3000 \mathrm{~g}$ for $10 \mathrm{~min}$ and the aqueous phase was analyzed by HPLC.

Atenolol concentrations were quantified according to a HPLC-UV detection method in a Waters chromatographic system (Waters, Mississauga, ON, Canada). The analytical technique of Lefebvre et al was adapted for this purpose (12). The mobile phase consisted of methanol $(\mathrm{MeOH})$, distilled water and glacial acetic acid (28:71:1). The flow rate was set to $1 \mathrm{~mL} / \mathrm{min}$ through the column (Wolf Nucleosil 5 C-18 100A $150 \times 4,6 \mathrm{~mm})$, and peaks were monitored with a UV detector at $\lambda=270 \mathrm{~nm}$. Quantification of atenolol was obtained by plotting the height obtained for each sample against a calibration curve. Limit of quantitation (LOQ) for this chromatographic method was determined by the lowest point of calibration curve and as such was established at $400 \mathrm{ng} / \mathrm{mL}$. Relationship between peak height and atenolol concentration were found to be linear between $400 \mathrm{ng} / \mathrm{mL}$ and $40000 \mathrm{ng} / \mathrm{mL}\left(r^{2}\right.$ $=0.99$ ). Coefficients of variation for low and high concentration quality controls were $17.2 \%$ and $8 \%$, respectively. Nonstereospecific analysis was used for quantitation of all drugs.

\section{In vivo drug clearance}

Atenolol $\mathrm{CL}_{\mathrm{D}}$ in vivo was calculated as arterial and venous plasma concentrations measured by HPLC$\mathrm{UV}$ at each sampling time.

Arterial plasma flow $\left(Q_{\mathrm{pa}}\right)$ was measured as:

$$
Q_{\mathrm{pa}}=Q_{\mathrm{a}} \times\left(1-\mathrm{HCT}_{\mathrm{a}}\right)
$$

where $Q_{\mathrm{a}}$ was arterial blood flow, and $\mathrm{HCT}_{\mathrm{a}}$ was patient arterial hematocrit.

Venous plasma flow $\left(Q_{\mathrm{pv}}\right)$ was determined as:

$$
Q_{\mathrm{pv}}=Q_{\mathrm{pa}}-\operatorname{UFR}(\mathrm{ml} / \mathrm{min})
$$

For each sampling time, $\mathrm{CL}_{\mathrm{D}}$ was calculated as:

$$
\mathrm{CL}_{\mathrm{D}}=\left[\left(Q_{\mathrm{pa}} \times C_{\mathrm{a}}\right)-\left(Q_{\mathrm{pv}} \times C_{\mathrm{v}}\right)\right] / C_{\mathrm{a}}
$$

where $C_{\mathrm{a}}$ and $C_{\mathrm{v}}$ were arterial and venous plasma atenolol concentrations, respectively. Average $C_{D}$ was ascertained by the Trapeze area integration method.

\section{STATISTICS}

Curve fittings of the elimination kinetics (concentrations vs. time with standard deviations) are illustrated in Figures 2 and 3 (see results) where a non-linear regression with exponential decay equation was applied with SigmaPlot 12 (Systat Software Inc., Chicago, IL, USA). The curve-fitting equation was:

$$
C_{p}(t)=C_{p}(0) e^{-k t}
$$


This is a single equation with two parameters: $\mathrm{C}_{p} 0$ and $\mathrm{k}$ where the initial concentration was set at $100 \%\left(C_{p}(0)=100\right)$, and $\mathrm{k}$ was superior to 0 . The exponential regression curve had a correlation coefficient (r) of 0.914 in vivo and 0.8331 in vitro with a $P$ value $=0.0001$.

The intervals of prediction are calculated from the extreme values of the observed data. Using SigmaPlot 12 (Systat Software Inc., Chicago, IL, USA) tools, a prediction band relating to the exponential regression with a $95 \%$ confidence was traced for each curve (in vivo and in vitro) and showed that at the end of dialysis, starting roughly at around 80 minutes, the curve fit for in vivo is included within the prediction band of the in vitro. Hence we consider that the in vitro model is acceptable to predict the elimination during dialysis.

\section{RESULTS}

\section{In vivo dialysis}

Figure 2 reports arterial plasma concentrations in patients (expressed as percentages of initial arterial concentrations) and corresponding curve fittings. Data on patient $\# 3$ at $60 \mathrm{~min}$ and patient $\# 5$ at 30 min were discarded because they respectively represented $107 \%$ and $230 \%$ of initial concentration, which was impossible as the drug underwent elimination. Figure 2 also shows virtually identical elimination curves for patients \#3 and \#5. Figure 3 depicts mean in vivo concentrations $v s$. time, including standard deviations.

$\mathrm{CL}_{\mathrm{D}}$ data, calculated from the dialysis parameters of each patient, are presented in Table 2. $\mathrm{CL}_{\mathrm{D}}$ ranged from 162 to $311 \mathrm{~mL} / \mathrm{min}$, excluding patient \#2 (see Discussion for details).


Figure 2. Curve fitting of initial atenolol concentration percentages $v s$. time in 6 patients studied. $\%$ of $\mathrm{Cp}(0)=$ percentage of initial arterial concentration. 
Table 2. Atenolol Dialysis Clearance In Vivo and In Vitro

\begin{tabular}{|c|c|c|c|c|c|c|c|c|}
\hline & & & Dialysis C & rance $(\mathrm{m})$ & in) \pm err & & & \\
\hline & & & & & & & In vitro & \\
\hline Patient 1 & Patient 2 & Patient 3 & Patient 4 & Patient 5 & Patient 6 & Dialysis1 & Dialysis2 & Dialysis3 \\
\hline $162 \pm 50$ & $82 \pm 25$ & $311 \pm 96$ & $236 \pm 73$ & $236 \pm 73$ & $230 \pm 71$ & $193 \pm 13$ & $198 \pm 13$ & $201 \pm 13$ \\
\hline
\end{tabular}

\section{In vitro dialysis}

Figure 3 shows mean in vitro concentrations vs. time (including standard deviations) with corresponding curve fitting. Atenolol was significantly removed from the buffer within the time period studied, especially during the first hour of dialysis. By the end of dialysis, atenolol remaining in the drug reservoir was less than $2 \%$ of initial arterial concentration. Mean in vitro $\mathrm{CL}_{\mathrm{D}}$ was $198 \pm 4 \mathrm{~mL} / \mathrm{min}$.

\section{DISCUSSION}

Our study compared the atenolol elimination kinetics of $6 \mathrm{HD}$ patients with 3 in vitro highpermeability dialysis sessions using a physiological buffer containing BSA. BSA was chosen for financial reasons, as AGP is significantly more expensive. On the other hand, $\beta$-Blockers bind to both albumin and $\alpha$-acid glycoprotein (AGP) in plasma (13). Interactions between $\beta$-blockers and AGP are much stronger than with albumin $(13,14)$. However, atenolol is negligibly protein-bound (13, 15). Hence, the results should not be significantly affected by using BSA instead of AGP.

Figure 2 shows that drug removal in patient \#2 was much slower than in other patients, with $C L_{D}$ of $82 \mathrm{~mL} / \mathrm{min}$, which could probably be explained by misplacement of needles in his fistula. Moreover, it was recorded in this patient's chart that one of the needles exited the fistula during dialysis and a nurse had to reinsert it during dialysis. For these reasons, a decision was made not to include patient \#2 in Figure 3 which compares in vivo and in vitro elimination kinetics.

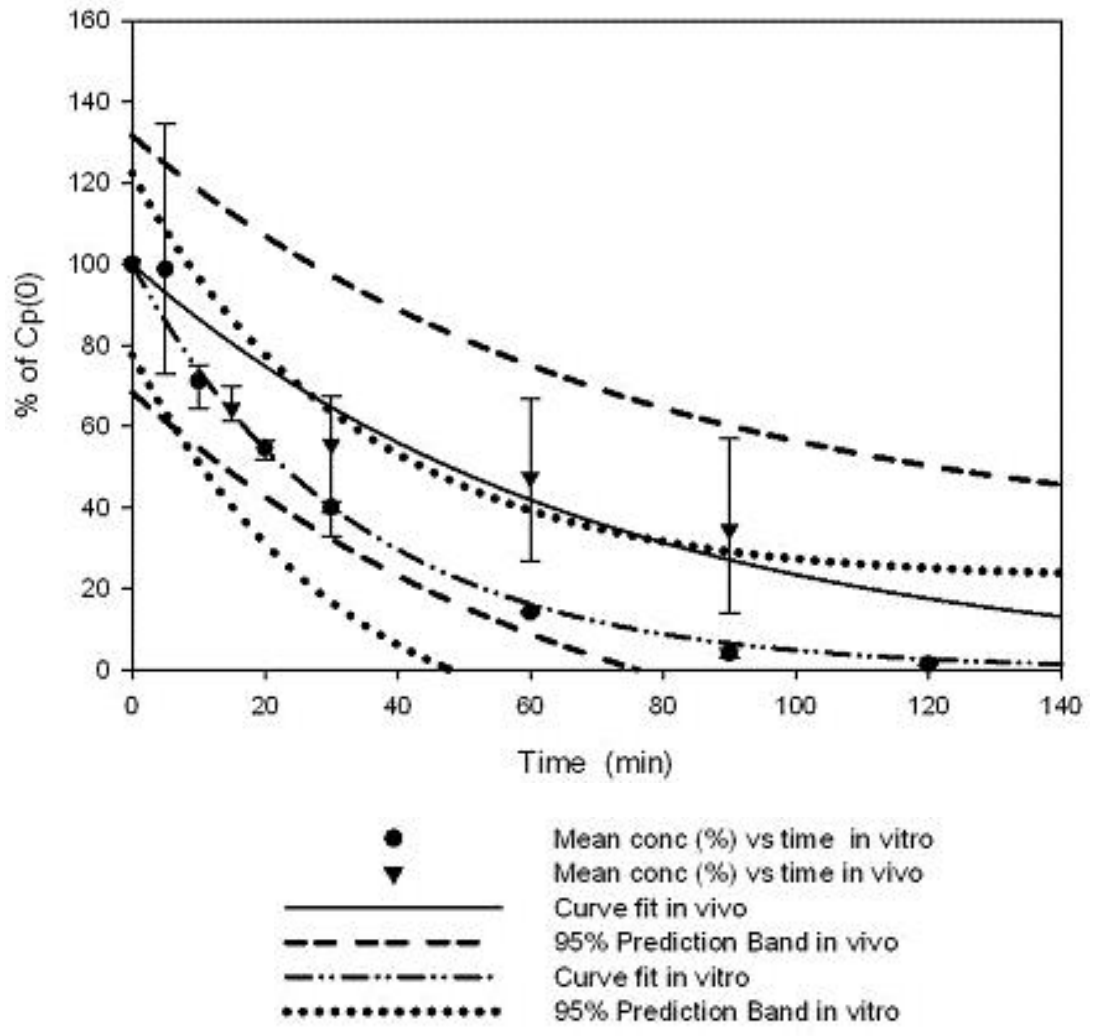

Figure 3. Mean concentration-time curve fittings in vivo and in vitro with standard deviation bars and $95 \%$ prediction intervals. $\%$ of $\mathrm{Cp}(0)=$ percentage of initial arterial concentration. 
Since 120-min sampling time was not available to all patients, it was also decided to present the results only up to $90 \mathrm{~min}$, in all figures and tables.

In the future, in order to decrease inter-patient variability, we would exclude patients with fistula problems (past or present) and also exclude patients that are prescribed low doses; this could ensure having the same sampling time for all. The plasma analysis would also benefit from using a more sensitive dosing method, (LC-MS) that we unfortunately did not have access to.

A significant impact of dialysis on drug elimination was expected since atenolol has a low molecular weight $(266.34 \mathrm{~g} / \mathrm{mol})$, is only minimally protein-bound $(6-16 \%)$, is hydrosoluble $(\log \mathrm{P}=$ $0.5)$ and has a low volume of distribution $(1.1 \mathrm{~L} / \mathrm{kg})$ (15-17). Indeed, in vivo $\mathrm{CL}_{\mathrm{D}}$ ranged between 162 and $311 \mathrm{~mL} / \mathrm{min}$, and in vitro between 193 and 201 $\mathrm{mL} / \mathrm{min}$ (Table 2). This observation reinforces the view that there is greater variability in vivo than in vitro. Several factors could explain the variability between patients, including polymorphism of both $\beta_{1}$-adrenergic receptors (18) and AGP (19), altered AGP levels (20), possible residual renal function, differences in dialysis conditions, dosage and dosing time.

During dialysis, mean arterial concentration decreased from $1.46 \mu \mathrm{g} / \mathrm{mL}$ at $0 \mathrm{~min}$ to $0.48 \mu \mathrm{g} / \mathrm{mL}$ at $90 \mathrm{~min}$ in 4 patients whose levels were recorded (patient \#2 was excluded as discussed previously, and the 90-min sample for patient \#1 was missing). As dialysis sessions usually last 3 to $4 \mathrm{~h}$ and atenolol therapeutic range is $0.2-0.5 \mu \mathrm{g} / \mathrm{mL}$, it is very likely that plasma atenolol levels decline under the therapeutic range at the end a dialysis session (21).

The initial concentration of atenolol in vitro is much higher than the initial concentration in vivo. These high concentrations in vitro do not saturate the filter since the high-permeability membranes used are very porous. Also, the solution was not saturated and there was no sedimentation in the solution during the experiments. Although the elimination is faster in vitro compared to in vivo at the beginning of the dialysis, the clearances calculated in vivo and in vitro are very high and are in the same range. Finally, at the end of dialysis, the drug is almost entirely eliminated in both cases.

In 1980, Flouvat et al. studied the pharmacokinetics of atenolol taken orally by 12 patients undergoing dialysis for 5-7 h by coil kidney with cuprophane membrane (22). They reported a mean half-life of $7.5 \pm 3.7 \mathrm{~h}$ and plasma clearance rate of $42.6 \pm 21.3 \mathrm{~mL} / \mathrm{min}$ during dialysis (22). Our experiment, on 6 patients undergoing highpermeability hemodialysis for 3-4 h, revealed a mean half-life of $1.5 \pm 1 \mathrm{~h}$ and plasma clearance rate of $235 \pm 53 \mathrm{~mL} / \mathrm{min}$ during dialysis. These results re-emphasize the fact that, drug elimination is closely related to the type of filtration membrane and high-permeability membranes are very efficient in clearing blood.

In Figure 3, with addition of a 95\% prediction interval to the in vitro elimination curve, we noted that the in vivo elimination curve was included in this interval after $80 \mathrm{~min}$ until the end of the dialysis. Between 30 and $80 \mathrm{~min}$, the in vivo elimination curve was very close to the upper limit of the prediction interval, most probably because of the incompleteness of the drug absorption process in some patients. In fact, the reported time to peak concentration after oral atenolol is 2 to $4 \mathrm{~h}$, and patients are dosed 1 to $2 \mathrm{~h}$ prior to HD (23). It is of paramount importance to mention that this in vitro model predicts the elimination of virtually the entire atenolol dose, that is to say, approximately 80 to $100 \%$ after $2 \mathrm{~h}$ of dialysis and the in vivo curve is found in this prediction interval (Figure 3). Consequently, HD patients would probably benefit from dosing adjustment after a 3-4 h highpermeability dialysis session.

Our study has indicated that atenolol is almost entirely cleared during high-permeability hemodialysis. Furthermore, the in vitro study can categorize qualitatively if the drug is highly dialyzable or low dialyzable. Using this in vitro validated model, it is now possible to conduct further research in finding a faster way to estimate drug clearance without having to replicate these studies for all therapeutic agents.

\section{ACKNOWLEDGEMENTS}

The authors are grateful to Pharmascience Inc. for study sponsorship. The authors would like also to thank the hemodialysis staff at the Jewish General Hospital for technical assistance and Prof. Grégoire Leclair at Université de Montréal for his support in drug analysis.

\section{REFERENCES}

1. Bailie GR, Mason NA, Ghannoum M. Dialysis of Drugs. CKD Insights, LLC, Verona, WI, USA, 2011 . 
2. USRDS 2011 Annual Data Report: Atlas of Chronic Kidney Disease and End-Stage Renal Disease in the United States. National Institutes of Health, National Institute of Diabetes and Digestive and Kidney Diseases, Bethesda, MD, USA, 2011;218-219.

3. Sood MM, Battistella M, Lok CE. Patterns of cardioprotective medication prescription in incident hemodialysis patients. Int Urol Nephrol, 2009; 41(4):1021-1027.

4. Santos SFF, Peixoto AJ. Hypertension in dialysis. Curr Opin Nephrol Hypertens, 2005; 14(2):111-118.

5. Furgeson SB, Chonchol M. beta-blockade in chronic dialysis patients. Seminars in Dialysis, 2008; 21(1):43-48.

6. Cice G, Ferrara L, D'Andrea A, D'Isa S, Di Benedetto A, Cittadini A, Russo PE, Golino P, Calabro R. Carvedilol increases two-year survival in dialysis patients with dilated cardiomyopathy - A prospective, placebo-controlled trial. J Am Coll Cardiol, 2003; 41(9):1438-1444.

7. Rowland M, Tozer TN. Clinical Pharmacokinetics: concepts and applications. Lippincott Williams \&Wilkins, Philadelphia, PA, USA, 1995.

8. Hudson JQ, Comstock TJ, Feldman GM. Evaluation of an in vitro dialysis system to predict drug removal. Nephrol Dial Transplant, 2004; 19(2):400405.

9. Maynor LM, Carl DE, Matzke GR, Gehr TWB, Farthing C, Farthing D, Brophy DF. An in vivo-in vitro study of cefepime and cefazolin dialytic clearance during high-flux hemodialysis. Pharmacotherapy, 2008; 28(8):977-983.

10. Krebs-Henseleit (KH) Buffer, Cold Spring Harbor Protocols

http://cshprotocols.cshlp.org/cgi/content/full/2006/4/ pdb.rec581?text_only=true Accessed May 4, 2010.

11. Yilmaz B, Asci A, Arslan S. Determination of metoprolol in human plasma and urine by highperformance liquid chromatography with fluorescence detection. J Sep Sci, 2010; 33(13):1904-1908.

12. Lefebvre MA, Girault J, Fourtillan JB. Betablocking-agents - determination of biological levels using high-performance liquid-chromatography. J Liq Chromatogr, 1981; 4(3):483-500.

13. Belpaire FM, Bogaert MG, Rosseneu M. Binding of beta-adrenoceptor blocking-drugs to human-serum albumin, to alpha-1-acid glycoprotein and to humanserum. Eur J Clin Pharmacol, 1982; 22(3):253-256.

14. Francesco B, Carmen C, Lucia G, Immacolata LRM. Enantioselective retention of beta-blocking agents on human serum albumin and alpha(1)-acid glycoprotein HPLC columns: Relationships with different scales of lipophilicity. Eur J Pharm Sci, 2009; 38(5):472-478.

15. Compendium of Pharmaceuticals and Specialities (CPS). Canadian Pharmacists Association, Ottawa, ON, Canada, 2011; 2480-2481.

16. Aronoff GR, Bennett WM, Berns JS, Brier ME, Kasbekar N, Mueller BA, Pasko DA, Smoyer WE. Drug Prescribing in Renal Failure-Dosing Guidelines for Adult and Children. American College of Physicians, Philadelphia, PA, USA, 2007.

17. Drug Bank : Open Data Drug \& Drug Target Database. Atenolol. http://www.drugbank.ca/drugs/DB00335. Accessed March 1, 2012.

18. Talameh JA, McLeod HL, Adams KF, Patterson JH. Genetic Tailoring of Pharmacotherapy in Heart Failure: Optimize the Old, While We Wait for Something New. J Card Failure, 2012; 18(4):338349.

19. Dente L, Pizza MG, Metspalu A, Cortese R. Structure and expression of the genes-coding for human alpha-1-acid glycoprotein. EMBO J. 1987; 6(8):2289-2296.

20. Delbaldo C, Chatelut E, Re M, Deroussent A, Seronie-Vivien S, Jambu A, Berthaud P, Le Cesne A, Blay JY, Vassal G. Pharmacokineticpharmacodynamic relationships of imatinib and its main metabolite in patients with advanced gastrointestinal stromal tumors. Clin Cancer Res. 2006; 12(20):6073-6078.

21. O'Grady J, Anderson S, Pringle D. Successful treatment of severe atenolol overdose with calcium chloride. CJEM, 2001; 3(3):224-7.

22. Flouvat B, Decourt S, Aubert P, Potaux L, Domart M, Goupil A, Baglin A. Pharmacokinetics of atenolol in patients with terminal renal-failure and influence of hemodialysis. Br J Clin Pharmacol, 1980; 9(4):379-385.

23. Micromedex 2.0 Database. Atenolol. Pharmacokinetics. Accessed May 30, 2012. 